\title{
Variáveis climáticas e o desempenho de um pivô central, em Cristalina Goiás
}

\author{
William Evangelista ${ }^{1}$, Carlos A. S. O liveira ${ }^{1} \&$ Cícero L. Silva $^{1}$
}

\begin{abstract}
RESU MO
O bjetivou-se, com este trabalho, avaliar o desempenho de um pivô central em função da velocidade do vento (VV), umidade relativa do ar (UR) e temperatura média do ar (T) e estabelecer um modelo estatístico para estimativa da eficiência de aplicação da água em função dessas variáveis independentes. Dados foram coletados nos períodos da manhã e tarde, em três épocas do ano ( 12 e 13/08/05; 22 e 23/09/05 e 27 e 28/10/05), considerando-se duas velocidades de deslocamento do equipamento, 50 e 100\%. 0 delineamento experimental foi 0 de blocos ao acaso para 0 fator velocidade do pivô com o fator época do ano em subparcelas e se considerando o período do dia como repetição. A pressão média no final da linha lateral foi de 137,3 kPa e próxima ao valor previsto pelo fabricante, ou seja, de 127,5 kPa. A lâmina média aplicada foi de 12 e de $5,7 \mathrm{~mm}$ para as velocidades de 50 e 100\%, respectivamente. Os coeficientes de uniformidade de Christiansen (CUC) calculados resultaram em valores considerados, na literatura, aceitáveis. As lâminas médias coletadas no período da manhã foram maiores que as coletadas no período da tarde. As variáveis independentes VV, T e UR, influenciaram o valor da eficiência de aplicação.
\end{abstract}

Palavras-chave: coeficiente de uniformidade, eficiência de distribuição, eficiência de aplicação, eficiência de irrigação

\section{Climatic variables and performance of center pivot at Cristalina, Goiás, Brazil}

\begin{abstract}
This research aimed to evaluate center pivot performance as a function of wind speed (VV), relative humidity of air (UR) and mean air temperature (T) and establish a stochastic model to estimate application efficiency as a function of these independent variables. Data were collected, during the morning and the afternoon period, and during three times of the year (August, 12 and 13; September, 22 and 23; and 0 ctober, 27 and 28, 2005), considering two speeds of outer driver unit (50 and 100\%). A randomized block design was used for factor speed of outer driver with factor time of the year as a split plot of factor speed, and considering period of the day as replication. The mean pressure head at the end of the lateral was $137.3 \mathrm{kPa}$ and close to the value predicted by the dealer of $127.5 \mathrm{kPa}$. The average water depths applied were 12 and $5.7 \mathrm{~mm}$ for 50 and $100 \%$ speed, respectively. Calculated Christiansen's uniformity coefficient (CUC) provided values considered in literature as standard. Average water depths collected in the morning period were greater than the ones collected in the afternoon. VV, T and UR independent variables influenced significantly water application efficiency values.
\end{abstract}

Key words: uniformity coefficient, distribution efficiency, application efficiency, irrigation efficiency 


\section{INTRODUÇÃO}

O sistema de irrigação por pivô central foi usado a primeira vez em 1950, porém sua expansão pelo mundo se deu a partir da década de 1980. Desde então, grandes avanços nesses sistemas foram incorporados, a exemplo da possibilidade de aplicação independente de água e de defensivos (King et al., 2009). No Brasil este sistema irriga uma área estimada de 651.548 ha, sendo a região centro oeste do País uma grande usuária deste sistema de irrigação. Por outro lado, pesquisando a literatura brasileira pertinente ao assunto, não se encontrou nenhum artigo sobre monitoramento da eficiência de irrigação na região centro oeste, evidenciando a necessidade de se estudar mais esses sistemas na mencionada região.

A economia de mão-de-obra e as altas produtividades estão entre as razões que justificam o uso do pivô central, desde que ocorram irrigações com frequência adequada e boa uniformidade (Bernardo et al., 2008). Diversas vantagens são destacadas no uso desses equipamentos de irrigação e uma delas é a possibilidade da completa automação do sistema, conforme o experimento de Peters \& Evett (2008), no qual descreveram um sistema de automação acionado segundo a temperatura da superfície foliar dos cultivos.

De acordo com Heinemann et al. (1998), devido à crescente necessidade de conservação e usos alternativos do recurso água; ao custo da energia; ao custo dos insumos e à estabilidade dos preços dos produtos agrícolas, os sistemas de irrigação, para serem vantajosos economicamente, devem proporcionar uma aplicação de água uniforme e eficiente. No pivô central é necessário, para se ter uma aplicação uniforme, que a vazão aplicada por unidade de comprimento aumente na medida em que se afaste do centro do pivô, implicando em aumento no diâmetro dos emissores.

Visando comparar as perdas de água por evaporação e deriva em um pivô central na cultura do milho, no estado do Kansas, USA, Olson \& Rogers (2008) testaram aplicações de água com difusores e com mangueiras perfuradas arrastadas junto à superfície do solo e concluíram que o uso da mangueira melhora a eficiência de irrigação, apesar do risco de entupimento.

A uniformidade de distribuição e a eficiência de aplicação de água dos sistemas de irrigação por aspersão são importantes parâmetros que expressam a qualidade da irrigação; assim, a avaliação de pivôs centrais deve, além da eficiência de aplicação, levar em consideração a uniformidade de distribuição de água ao longo da linha lateral consistindo da coleta das precipitações por meio de coletores (pluviômetros) instalados ao longo de uma linha radial, partindo do centro do pivô, numerados em ordem crescente e espaçados, um do outro, entre 4 e $6 \mathrm{~m}$ (Bernardo et al., 2008).

Keller \& Bliesner (1990) definem não apenas a eficiência de distribuição em função do coeficiente de uniformidade de Christiansen (CUC) e da área adequadamente irrigada (AAI), mas também a eficiência de aplicação pela relação entre a lâmina média coletada e a lâmina média emitida pelos aspersores. A eficiência de irrigação foi definida pelos mesmos autores a partir do produto de três eficiências: distri- buição, aplicação e condução, considerada igual a um, quando o equipamento não apresenta vazamento algum no sistema de condução.

Heermann \& Hein (1968) propuseram uma modificação na equação de Christiansen, para o cálculo do CUC, por considerarem que a uniformidade da lâmina aplicada não é somente função da diferença de pressão, mas também do aumento do diâmetro do emissor à medida em que este se afasta do centro da área irrigada. Exemplo da modificação proposta pode ser observado nos trabalhos de Zocoler et al. (2004).

Em testes de avaliação da uniformidade e da eficiência de aplicação em pivô central e se comparando o uso de uma linha e de quatro linhas, verificou-se ser suficiente o uso de apenas uma linha radial de coletores (Pinto et al., 2006). Esses autores constataram ainda, que variáveis climáticas como, por exemplo, a UR e a velocidade do vento, prevalentes durante uma irrigação, afetam a eficiência de aplicação.

Oliveira et al. (2004) analisando o coeficiente de uniformidade e a eficiência de aplicação de água em 11 pivôs centrais instalados no oeste da Bahia, encontraram valores variando de 67,6 a 92,4\%, para os coeficientes de uniformidade e de 80 a 99\% para a eficiência de aplicação. Devido às variabilidades encontradas justifica-se a necessidade de avaliações periódicas nesses sistemas de irrigação.

Objetivou-se, com este trabalho, avaliar o desempenho de um sistema de irrigação tipo pivô central, em Cristalina, Goiás, proporcionado pelas características hidráulicas do equipamento e pelas variáveis climáticas locais VV, UR e T, e estabelecer um modelo estatístico que leve em conta o efeito dessas variáveis sobre o desempenho do equipamento, de forma a usá-lo em previsões da eficiência de irrigação.

\section{MATERIAL E MÉTODOS}

Utilizou-se um pivô central instalado na empresa Agrícola Wehrmann, localizada no município de Cristalina, GO, com coordenadas geográficas $17^{\circ} 02^{\prime} 45^{\prime \prime}$ de latitude sul e $47^{\circ} 45^{\prime} 24^{\prime \prime}$ de longitude oeste e $980 \mathrm{~m}$ de altitude. Os solos do local são do tipo Latossolo Vermelho-amarelo de textura média. O relevo é suavemente ondulado a plano. A precipitação e a temperatura média anual são, respectivamente, $1300 \mathrm{~mm}$ e $20,9^{\circ} \mathrm{C}$.

A linha lateral do pivô central é composta de 12 torres. No trecho correspondente às três primeiras torres o diâmetro da linha lateral é de $219 \mathrm{~mm}$; no trecho seguinte, de seis torres, o diâmetro é de $200 \mathrm{~mm}$ e, no último trecho, com três torres, é de $169 \mathrm{~mm}$; após a última torre, um balanço com 25,50 m de comprimento e diâmetro variável, totalizou um raio efetivo de 588,10 m e abrangeu uma área circular irrigada de 108,65 ha. A linha lateral foi projetada para operar com uma pressão de $418,74 \mathrm{kPa}$ na entrada da torre central e de 127,48 kPa no final da linha. A linha lateral também apresenta tubos de descida ou bengalas de PVC flexível espaçados 2,20 m entre si. Os emissores Senninger "super spray", no final do tubo de descida, são providos de bocais de 1,59 a $10,32 \mathrm{~mm}$; defletores com 36 estrias com ranhuras e placa plana, posicionados a uma altura de 2,74 $\mathrm{m}$ do solo. 
A água é conduzida através de conjunto motobomba e uma rede adutora com $300 \mathrm{~mm}$ de diâmetro e $1300 \mathrm{~m}$ de comprimento. O conjunto motobomba é constituído de motor elétrico da marca WEG de 250 cv com 1750 rpm, acoplado a uma bomba centrífuga marca KSB mod. 150-50, cujo diâmetro do rotor é de $480 \mathrm{~mm}$. A vazão e a altura manométrica de projeto são, respectivamente, $452,67 \mathrm{~m}^{3} \mathrm{~h}^{-1}$ e $980,8 \mathrm{kPa}$. O equipamento, segundo informações do fabricante, tem capacidade nominal de aplicar uma lâmina bruta de $10,00 \mathrm{~mm} \mathrm{~d}^{-1}$ em um tempo de rotação de 24 h, com o relé percentual ajustado para 58\% da velocidade máxima de deslocamento.

Foram utilizados para coleta dos dados de precipitação do pivô, 180 pluviômetros da marca Fabrimar, fixados radialmente, distanciados entre si $3 \mathrm{~m}$, a $0,70 \mathrm{~m}$ de altura do solo e direcionados para a parte de maior aclive da área. As lâminas de água foram coletadas em duas velocidades de deslocamento do equipamento, a saber, nos percentuais de 100 e 50\% de sua capacidade máxima de deslocamento. Realizaram-se, para cada velocidade, dois testes, um com início às $6 \mathrm{~h}$ e o outro com início às $12 \mathrm{~h}$, visando quantificar o efeito da variação de fatores climáticos ao longo do dia. Em cada teste se registraram a velocidade do vento (VV), a umidade relativa (UR) e a temperatura do ar (T).

Objetivando estimar a vazão média do emissor (Qe), mediu-se a vazão de três emissores em cinco pontos da linha lateral: no início da parte aérea do equipamento, na metade do primeiro terço, na metade do segundo terço, na metade do terceiro terço e no final da linha lateral do pivô totalizando, assim, uma amostra de 15 emissores; nos mesmos pontos em que se efetuaram as medidas de vazão também se mediram as pressões.

Os testes foram realizados em três épocas do período seco do ano: 12 e 13/08; 22 e 23/09 e 27 e 28/10/2005, sendo o primeiro dia das mencionadas épocas para velocidade de deslocamento máxima $100 \%$ e o segundo dia para a velocidade de $50 \%$.

A eficiência de distribuição de água de irrigação, de acordo com Keller \& Bliesner (1990) foi estimada pela equação:

$$
\begin{aligned}
\mathrm{Ed}= & {\left[100+\left(606-24,9 \mathrm{AAI}+0,349 \mathrm{AAI}^{2}\right.\right.} \\
& \left.\left.-0,00186 \mathrm{AAI}^{3}\right)(1-\mathrm{CUC} / 100)\right]
\end{aligned}
$$

em que:

CUC - Coeficiente de uniformidade de Christiansen, \%

No presente trabalho se adotou o valor de $80 \%$ para a área adequadamente irrigada (AAI) o qual, substituído na equação anterior, resultou em:

$$
\mathrm{Ed}=100-104,7(1-\mathrm{CUC} / 100)
$$

Utilizou-se, para o cálculo do coeficiente de uniformidade de Christiansen, a equação modificada por Heermann \& Hein (1968) na forma:

$$
\mathrm{CUC}=100 \times\left[1-\frac{\sum_{\mathrm{i}=1}^{\mathrm{n}} \mathrm{S}_{\mathrm{i}} \times\left|\mathrm{Y}_{\mathrm{i}}-\mathrm{Y}_{\mathrm{p}}\right|}{\sum_{\mathrm{i}=1}^{\mathrm{n}} \mathrm{S}_{\mathrm{i}} \times \mathrm{Y}_{\mathrm{i}}}\right]
$$

em que:

$\mathrm{Y}_{\mathrm{i}}$ - Lâmina coletada no pluviômetro i, mm

n - Número de coletores

$\mathrm{S}_{\mathrm{i}}$ - Distância do ponto do pivô ao ponto i, ou número do coletor

A lâmina média ponderada $\left(\mathrm{Y}_{\mathrm{p}}\right)$ foi calculada por:

$$
Y_{P}=\frac{\sum_{i=1}^{n} Y_{i} \times S_{i}}{\sum_{i=1}^{n} S_{i}}
$$

Outro parâmetro estimado foi a eficiência de aplicação da água, obtida pela relação entre a lâmina média coletada e a lâmina média emitida pelos emissores, expressa pela relação:

$$
\mathrm{Ea}=\mathrm{Lm} / \mathrm{La}
$$

em que:

Lm - Lâmina média de água coletada a 70 cm do solo, $\mathrm{mm}$

La - Lâmina média de água emitida pelos emissores, $\mathrm{mm}$

O cálculo de La foi realizado em função da vazão média dos emissores (Qe) em $\mathrm{m}^{3} \mathrm{~s}^{-1}$.

$$
\mathrm{La}=\frac{\mathrm{Ne} \times \mathrm{Qe} \times \mathrm{t}}{\mathrm{A}} \times 1000
$$

em que:

$$
\begin{aligned}
& \mathrm{Ne} \text { - Número de emissores } \\
& \mathrm{t} \text { - Tempo de rotação, s } \\
& \text { A - Área irrigada pelo equipamento, } \mathrm{m}^{2}
\end{aligned}
$$

Obteve-se a eficiência da irrigação (Ei) pelo produto das três eficiências; eficiência de distribuição, eficiência de aplicação e eficiência de condução, considerada igual a 1, pois o equipamento não apresentava nenhum vazamento no sistema de condução da água. A eficiência de irrigação foi obtida por meio da equação:

$$
\mathrm{Ei}=\mathrm{Ed} \times \mathrm{Ec} \times \mathrm{Ea}
$$

O delineamento utilizado foi em blocos completos casualizados para o fator velocidade do pivô na parcela, o fator época em subparcela e período do dia, constituindo as repetições.

Análises de regressão foram realizadas para estabelecer um modelo considerando-se variáveis independentes a velocidade do vento, a temperatura e a umidade relativa.

\section{RESULTADOS E DISCUSSÃO}

Os valores médios de todas as variáveis independentes e dependentes analisadas podem ser observados na Tabela 1. Os valores de CUC, Ea, Ed, e Ei resultantes estão, em sua maioria com valores aceitáveis, de acordo com a literatura. 
Tabela 1. Valores médios das variáveis independentes: velocidade do vento (VV), temperatura (T), umidade relativa (UR); e das variáveis dependentes: lâmina média (Lm), coeficiente de uniformidade de Christiansen (CUC), eficiência de distribuição (Ed), eficiência de aplicação (Ea) e eficiência de irrigação (Ei), em função de velocidades de deslocamento (50 e 100\%), períodos do dia (Manhã e Tarde) nas épocas 12 e 13/08; 22 e 23/09; e 27 e 28/10/2005, observados em um pivô central, Cristalina, GO

\begin{tabular}{|c|c|c|c|c|c|c|c|c|c|c|}
\hline $\begin{array}{l}\text { Vel do pivô } \\
(\%)\end{array}$ & Período & Época & $\underset{\left(m s^{-1}\right)}{V V}$ & $\begin{array}{l}\text { Temp. } \\
\left({ }^{\circ} \mathrm{C}\right)\end{array}$ & $\begin{array}{l}\text { UR } \\
(\%)\end{array}$ & $\underset{(\mathrm{mm})}{\mathrm{Lm}}$ & $\begin{array}{l}\text { CUC } \\
(\%)\end{array}$ & $\begin{array}{l}\text { Ed } \\
(\%)\end{array}$ & $\begin{array}{l}\mathrm{Ea} \\
(\%)\end{array}$ & $\begin{array}{c}\mathrm{Ei} \\
(\%)\end{array}$ \\
\hline \multirow{6}{*}{100} & M & 1 & 1,1 & 15,3 & 69 & 5,9 & 91 & 91 & 94 & 86 \\
\hline & $\mathrm{T}$ & 1 & 1,8 & 27,9 & 38 & 4,9 & 85 & 85 & 77 & 66 \\
\hline & M & 2 & 0,3 & 19,3 & 57 & 6,1 & 90 & 89 & 97 & 87 \\
\hline & $\mathrm{T}$ & 2 & 1,1 & 34,8 & 28 & 6,1 & 91 & 90 & 96 & 87 \\
\hline & M & 3 & 0,4 & 18,2 & 65 & 5,8 & 83 & 82 & 93 & 76 \\
\hline & $T$ & 3 & 0,9 & 35,0 & 24 & 5,7 & 91 & 90 & 90 & 81 \\
\hline \multirow{6}{*}{50} & M & 1 & 0,5 & 16,5 & 55 & 12,2 & 91 & 90 & 89 & 80 \\
\hline & $\mathrm{T}$ & 1 & 2,8 & 31,0 & 20 & 12,0 & 93 & 92 & 87 & 80 \\
\hline & $M$ & 2 & 1,9 & 20,4 & 71 & 11,9 & 90 & 90 & 86 & 78 \\
\hline & $\mathrm{T}$ & 2 & 3,5 & 31,2 & 30 & 10,5 & 91 & 90 & 76 & 69 \\
\hline & $M$ & 3 & 0,3 & 20,7 & 71 & 13,7 & 90 & 89 & 99 & 89 \\
\hline & $\mathrm{T}$ & 3 & 1,3 & 31,3 & 41 & 11,8 & 90 & 90 & 86 & 78 \\
\hline
\end{tabular}

Para a velocidade de deslocamento do pivô de $100 \%$ e as três épocas estudadas foram observadas lâminas médias de: 5,9; 6,1 e 5,8 mm, no período da manhã e 4,9; 6,1 e 5,7 mm no período da tarde. Observa-se que esses valores estão próximos da média de $5,7 \mathrm{~mm}$, projetada pelo fabricante. Para a velocidade de deslocamento de $50 \%$, as lâminas médias foram 12,2; 11,9 e 13,7 mm para o período da manhã e 12,0; 10,5 e $11,8 \mathrm{~mm}$ para o período da tarde.

Os valores médios de Lm, CUC, Ed, Ea e Ei observados no período da manhã não diferiram significativamente daqueles observados à tarde (Tabela 2); todavia, por razões óbvias a variável lâmina média diferiu em função da velocidade de deslocamento. Houve diferenças entre as variáveis independentes UR, VV e T, em função do período do dia e do ano, sugerindo que essas variáveis podem ser responsáveis pela variação das variáveis dependentes analisadas, em especial a Ea que, apesar de não ter sido significativa a 5\%, o foi a $5,5 \%$ de probabilidade.

Tabela 2. Resumo da análise de variância para umidade relativa (UR), velocidade do vento (VV), temperatura do ar (T), lâmina média (Lm), coeficiente de uniformidade (CUC), eficiência de distribuição (Ed), eficiência de aplicação de água (Ea) e eficiência de irrigação (Ei). Duas velocidades de deslocamento $(\mathrm{Vd})$ do pivô (50 e 100\%), três épocas (E) e duas repetições, manhã e tarde (M/T)

\begin{tabular}{ccccccccc}
\hline $\begin{array}{c}\text { Fonte de } \\
\text { variação }\end{array}$ & UR & VV & T & Lm & CUC & Ed & Ea & Ei \\
M/T & $*$ & NS & NS & NS & NS & NS & NS & NS \\
Vd & NS & NS & NS & $*$ & NS & NS & NS & NS \\
E & NS & $*$ & $*$ & NS & NS & NS & NS & NS \\
Vd xE & $*$ & $*$ & NS & NS & NS & NS & NS & NS \\
\hline
\end{tabular}

* significativo a $5 \%$ de probabilidade pelo teste de Tukey; NS - não significativo a $5 \%$ de probabilidade

Os perfis médios de distribuição de água ao longo do pivô encontram-se na Figura 1. Analisando-se a aplicação de água do pivô central, observa-se que houve, nas três épocas, diferenças entre as lâminas coletadas nas manhãs com as lâminas coletadas no período da tarde. As lâminas coletadas nas manhãs tenderam a ser maiores que as coletadas no período da tarde. Este fato está relacionado com os fatores climáticos UR, VV e T, conforme evidenciado na Tabela 1, variáveis estas que favorecem o aumento da demanda evaporativa no período da tarde e causam maiores perdas por evaporação.

Pode-se constatar, com o auxílio da Tabela 3, que o equipamento estudado apresentou um problema de homogeneidade de pressão muito grande ao longo da linha lateral, mesmo após a passagem da água pelo regulador de pressão; todavia, o fabricante não informou a pressão de serviço necessária nos diversos trechos da linha lateral o que impediu de se apresentar discussões mais detalhadas sobre o ocorrido, fato também evidenciado por Lima et al. (2003). Comparando-se a terceira coluna com a última da Tabela 3, evidencia-se que o desempenho dos reguladores foi apenas razoável pois se esperava uma pressão, após o regulador, em torno de 127,4 kPa. Os únicos pontos nos quais a pressão de serviço ficou próxima ao esperado foram nos últimos emissores porém, aparentemente, essa heterogeneidade de pressão nos emissores iniciais não afetou significativamente a uniformidade de distribuição de água.

As frequências acumuladas das lâminas coletadas em função do período do dia, época do ano e velocidade de rotação, estão resumidas na Figura 2. As menores frequências acumuladas foram observadas com a velocidade de desloca-

Tabela 3. Distância do centro do pivô, número de ordem dos três emissores, nas distâncias consideradas, e pressão média de serviço na base das bengalas (sem regulador de pressão) e após os reguladores de pressão, ao longo da linha lateral do pivô

\begin{tabular}{cccc}
\hline $\begin{array}{c}\text { Distância do } \\
\text { centro }(\mathbf{m})\end{array}$ & $\begin{array}{c}\text { Ordem dos } \\
\text { emissores }\end{array}$ & $\begin{array}{c}\text { Pressão s/ } \\
\text { regulador }(\mathbf{k P a})\end{array}$ & $\begin{array}{c}\text { Pressão c/ } \\
\text { regulador }(\mathbf{k P a})\end{array}$ \\
\hline 11 & $4^{0}, 5^{\circ}$ e $6^{\circ}$ & 441,30 & 362,85 \\
88 & $39^{\circ}, 40^{\circ}$ e $41^{\circ}$ & 402,07 & 343,23 \\
275 & $124^{\circ}, 125^{\circ}$ e $126^{\circ}$ & 274,58 & 274,58 \\
468,6 & $212^{\circ}, 213^{\circ}$ e $214^{\circ}$ & 205,94 & 196,13 \\
588,1 & $266^{\circ}, 267^{\circ}$ e $268^{\circ}$ & 186,33 & 137,29 \\
\hline
\end{tabular}




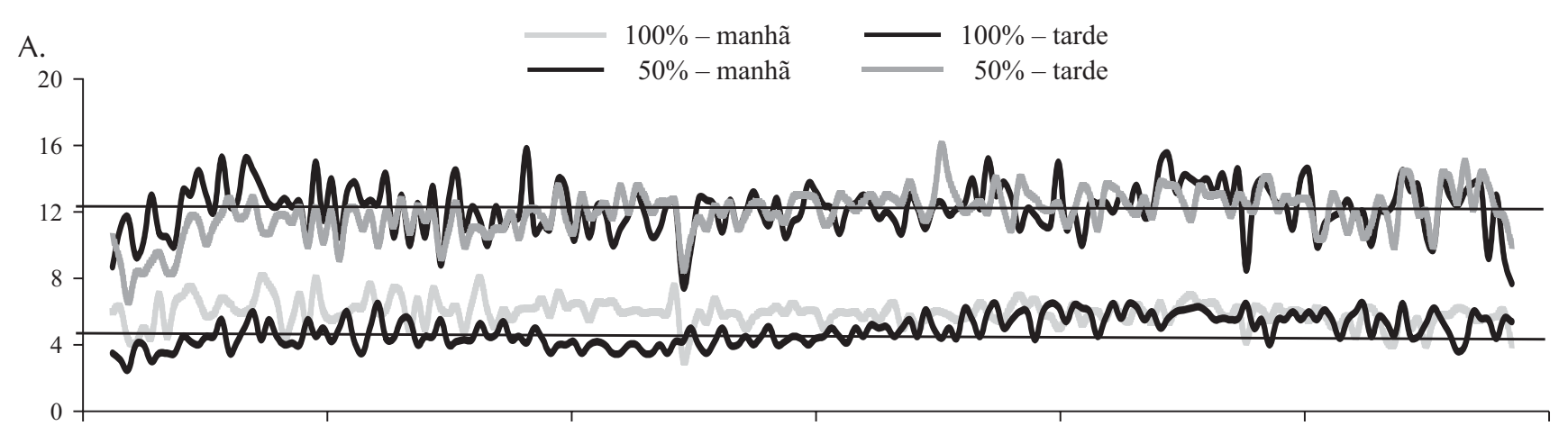

B.

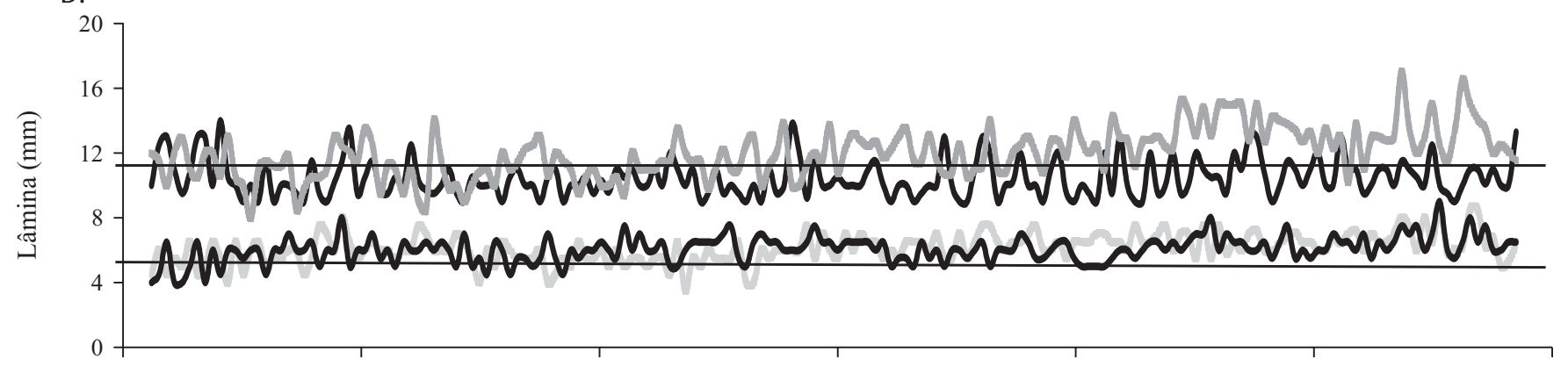

C.

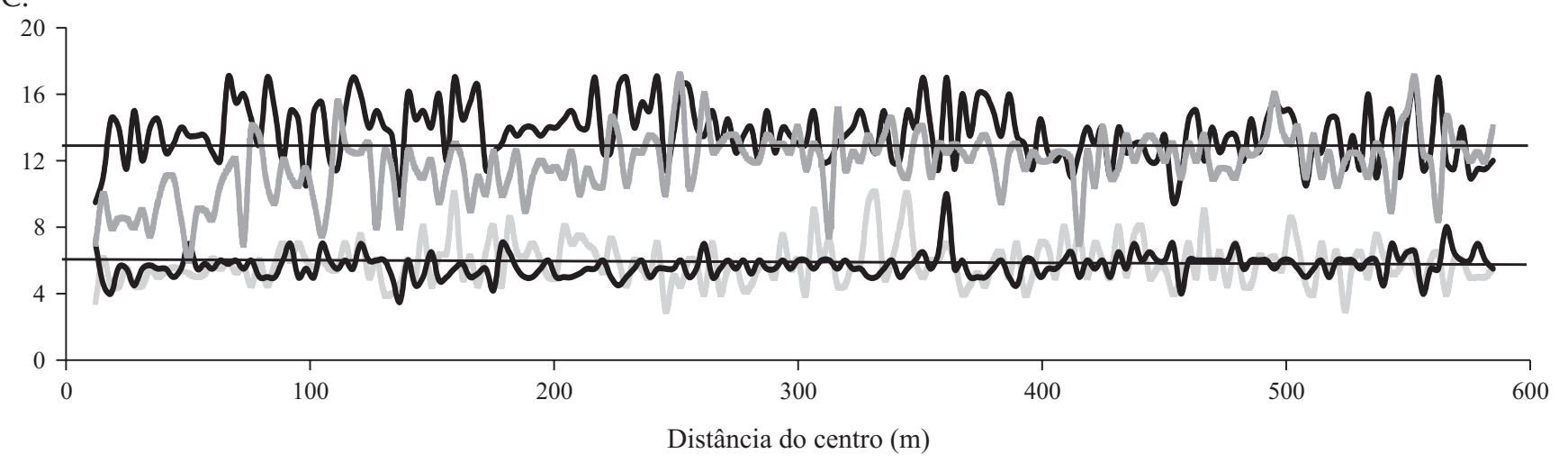

Figura 1. Distribuição da lâmina de água em três épocas: 12 e 13/08 (A); 22 e 23/09 (B); e 27 e 28/10/2005 (C) em função de duas velocidades de deslocamento (50 e 100\%), dois períodos do dia (manhã e tarde) e as lâminas média do pivô, observadas em Cristalina, GO

mento máxima do pivô e no período da tarde (Figura 2A e B) e as maiores frequências foram notadas na velocidade de deslocamento de 50\% (Figura 2C e D).

Para melhor correlação das frequências com que as lâminas coletadas foram aplicadas na área irrigada com a área adequadamente irrigada, foi definida uma $\mathrm{L}_{80 \%}$ que é a lâmina mínima coletada em $80 \%$ da área irrigada. Para o pivô em sua velocidade máxima, a $\mathrm{L}_{80 \%}$ na primeira, segunda e terceira época foi, respectivamente, 5,52; 5,53 e 5,03 mm no período da manhã e 4,10; 5,61 e 5,13 mm no período da tarde; já a 50\% da velocidade máxima de deslocamento do equipamento, as $\mathrm{L}_{80 \%}$ foram 11,01; 9,58 e 12,15 mm no período da manhã e 11,$01 ; 10,90$ e 10,49 mm para o período da tarde: entretanto, só no período da manhã é que se observou nítida variação entre as três épocas estudadas, o que está em consonância com a interação entre velocidade de deslocamento e época do ano para as variáveis independentes UR e VV (Tabela 2).

Os coeficientes de uniformidade de Christiansen (CUC) obtidos se situaram dentro do intervalo que Bernardo et al. (2008) consideram bons, ou seja, de 80 a 90\% (Tabela 1); uma vez que o CUC não foi afetado pelas variáveis climáticas independentes, tal fato pode estar relacionado com o espaçamento entre as bengalas ou difusores da linha lateral de 2,20 m, e não de 3,20 m, como eram projetados os pivôs anteriores a este modelo o que, provavelmente, proporcionou uma sobreposição melhor dos jatos de água dos emissores, ocasionando também melhor uniformidade de distribuição da lâmina aplicada.

Os valores da eficiência de aplicação e de irrigação também estão dentro do intervalo considerado adequado na literatura (Tabela 1 ).

Utilizando-se a análise de regressão múltipla para verificar a influência dos referidos parâmetros na eficiência de aplicação, verificam-se 99,8\% de probabilidade de que as diferenças da eficiência de aplicação sejam explicadas pelas diferenças nos parâmetros climáticos mencionados (Tabela 4). 

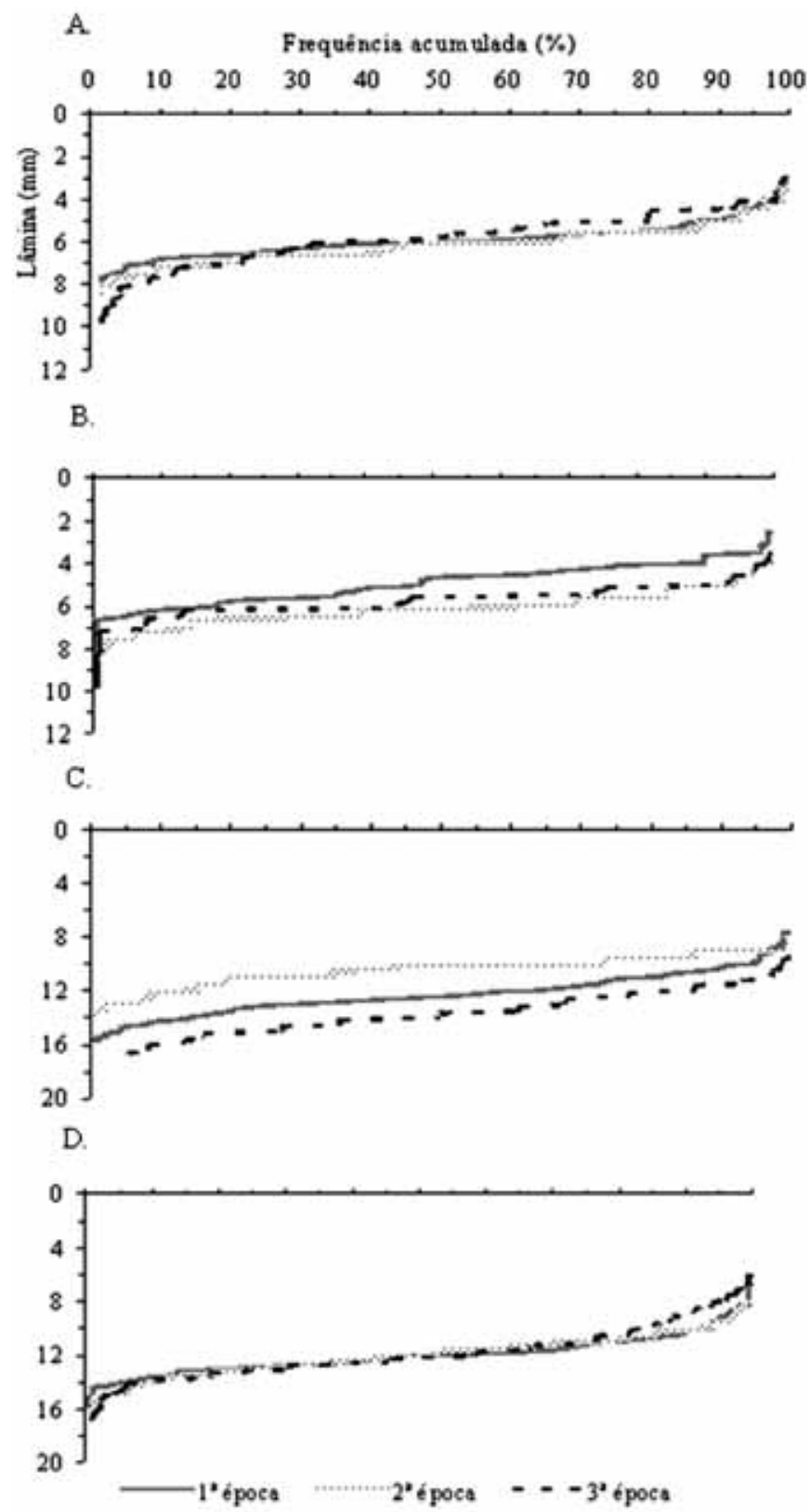

Figura 2. Frequências acumuladas da lâmina de água a $100 \%$ de velocidade de deslocamento, obtidas de manhã (A) e à tarde (B) e freqüências acumuladas a $50 \%$ da velocidade de deslocamento, obtidas de manhã (C) e tarde (D), em três épocas do ano

Com os coeficientes envolvendo as variáveis climáticas, o teste t de Student e a probabilidade (Tabela 5), conclui-se haver dupla e tríplice interação envolvendo a variável velo-

Tabela 4. Análise de variância da regressão múltipla para a variável dependente eficiência de aplicação de água em função das variáveis: velocidade do vento, temperatura e umidade relativa do ar

\begin{tabular}{crrrcc}
\hline $\begin{array}{c}\text { Fonte de } \\
\text { Variação }\end{array}$ & GL & SQ Total & \multicolumn{1}{c}{ SQM } & F & Probabilidade \\
Regressão & 5 & 550,0498 & 110,0099 & 16,66 & $0,002^{* *}$ \\
Resíduo & 6 & 39,6169 & 6,6028 & & \\
Total & 11 & 589,6667 & & & \\
\hline
\end{tabular}

** Significativo a $1 \%$ de probabilidade
Tabela 5. Valores dos coeficientes das variáveis independentes: velocidade do vento (VV), temperatura (T) e umidade relativa do ar (UR); do Teste t de Student e de probabilidade, obtidos através da análise de regressão múltipla, para a variável dependente eficiência de aplicação

\begin{tabular}{|c|c|c|c|}
\hline Fonte de Variação & $\begin{array}{l}\text { Coeficiente } \\
\text { da regressão }\end{array}$ & $\begin{array}{c}\text { Valor t } \\
\text { (Student) }\end{array}$ & Probabilidade \\
\hline W & $-6,429 \times 10^{1}$ & $-3,630$ & $0,004^{* *}$ \\
\hline$W \times U R$ & 1,218 & 4,371 & $0,001^{* *}$ \\
\hline $\mathrm{W} \times \mathrm{T}$ & 2,363 & 4,088 & $0,002^{* \star}$ \\
\hline$T \times U R$ & $1,700 \times 10^{-2}$ & 2,750 & $0,019 *$ \\
\hline WxT $x$ UR & $-5,446 \times 10^{-2}$ & $-5,170$ & $0,000 * *$ \\
\hline
\end{tabular}

Intercepto $=77,519 ;$ Coeficiente de determinação $\left(r^{2}\right)=0,933$

cidade do vento; apenas a dupla interação T x UR foi significativa em nível de probabilidade maior que $1 \%$ enquanto as demais o foram em níveis menores que $1 \%$.

Assim, foi possível estabelecer a equação de estimativa da Ea, em função das variáveis independentes, com $\mathrm{r}^{2}$ igual a 0,93, na forma:

$$
\begin{aligned}
& \mathrm{Ea}=77,519-64,29 \mathrm{VV}+1,218 \mathrm{VV} \mathrm{UR}+2,363 \mathrm{VV} \mathrm{T} \\
& \quad+1,700 \times 10^{-2} \mathrm{~T} \mathrm{UR}-5,446 \times 10^{-3} \mathrm{VV} \mathrm{T} \mathrm{UR} \\
& 0,3 \mathrm{~m} \mathrm{~s}^{-1} \leq \mathrm{VV} \leq 3,5 \mathrm{~m} \mathrm{~s}^{-1} ; \quad 15,3{ }^{\circ} \mathrm{C} \leq \mathrm{T} \leq 35^{\circ} \mathrm{C} ; \\
& 20 \% \leq \mathrm{UR} \leq 71 \%
\end{aligned}
$$

Este modelo apresenta problemas de multicolinearidade, fazendo com que os valores de probabilidade (Tabela 5) sejam artificialmente maiores que os que aconteceriam se ela não ocorresse; entretanto, a multicolinearidade não é um problema ou não afeta a variância do preditor, quando o objetivo da análise de regressão é fazer inferências sobre a previsão de novas informações, dentro do intervalo abrangido pelas variáveis independentes (Neter \& Wasserman, 1974); além disso, deve-se lembrar de que o déficit de saturação do ar aumenta na medida em que $\mathrm{T}$ aumenta, mesmo para um valor de UR constante, ajudando a explicar a manutenção dessas variáveis no modelo estatístico, apesar da multicolinearidade existente.

É necessário realçar que este modelo não pode ser generalizado para outros tipos de equipamentos ou mesmo diferente espaçamento entre bengalas, tipo de defletor, pressão de operação do emissor etc. Simulações em que se usa o modelo com os dados observados por Pinto et al. (2006) não forneceram resultados satisfatórios.

Com o auxílio desta equação se construiu a Tabela 6, na qual se apresentam os valores médios das eficiências de aplicação observados e calculados. Verificou-se um ajuste muito bom entre os valores de Ea observados e calculados, conforme se evidencia na Tabela 6 e na Figura 3, indicando que o modelo estatístico possui um potencial muito bom para estimativa da eficiência de aplicação no equipamento testado, dentro das amplitudes observadas para as variáveis climáticas. Através da equação ajustada (Figura 3) constata-se, a partir de uma eficiência de $86 \%$, que o modelo utilizado para a estimativa da eficiência de aplicação tende a subestimar os valores observados. 
Tabela 6. Valores de eficiência de aplicação (Ea) observados e cal culados usando-se a equação de regressão múltipla e os respectivos resíduos para as duas velocidades de deslocamento do pivô

\begin{tabular}{cccccc}
\hline $\begin{array}{l}\text { Vel. do pivô } \\
\text { (\%) }\end{array}$ & Período & Época & $\begin{array}{c}\text { Ea observada } \\
\mathbf{( \% )}\end{array}$ & $\begin{array}{c}\text { Ea calculada } \\
\mathbf{( \% )}\end{array}$ & Resíduo \\
\hline 100 & M & 1 & 94 & 94 & 0,531 \\
& T & 1 & 77 & 78 & $-0,293$ \\
& M & 2 & 97 & 93 & 3,905 \\
& T & 2 & 96 & 93 & 3,498 \\
& M & 3 & 93 & 95 & $-2,323$ \\
& T & 3 & 90 & 93 & $-3,111$ \\
50 & M & 1 & 89 & 89 & $-0,236$ \\
& T & 1 & 87 & 87 & 0,137 \\
& M & 2 & 86 & 86 & 0,635 \\
& T & 2 & 76 & 76 & 0,566 \\
& M & 3 & 99 & 99 & 0,427 \\
& T & 3 & 86 & 86 & $-0,192$ \\
\hline
\end{tabular}

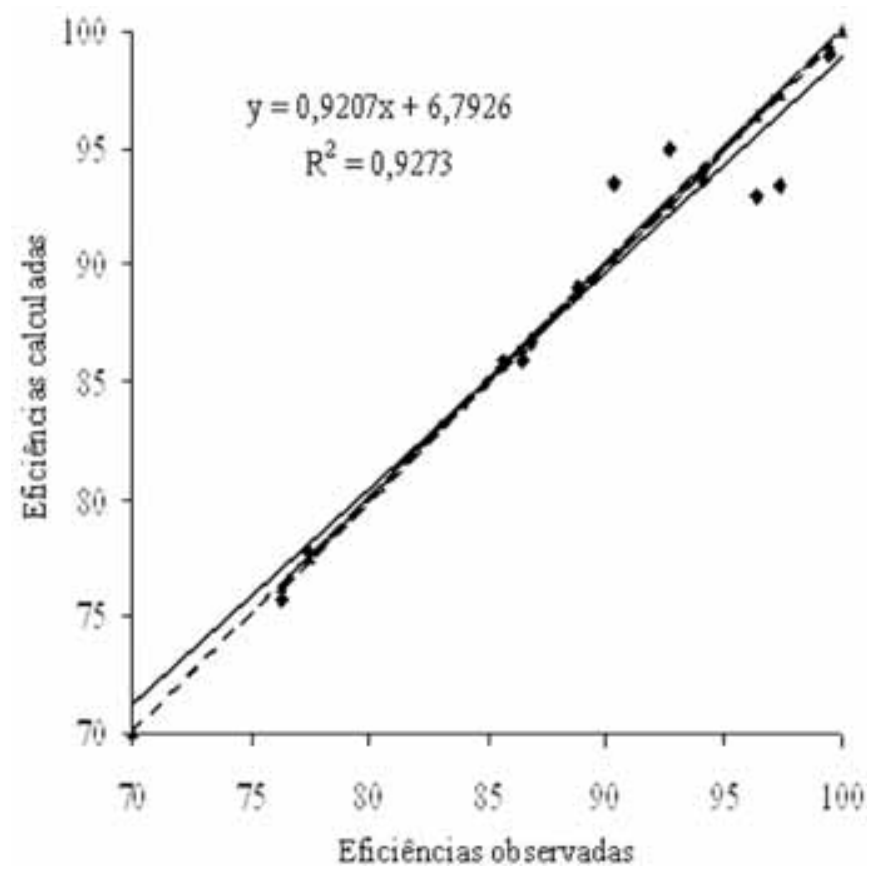

Figura 3. Dispersão entre valores das eficiências de aplicação de água observada e calculada

\section{CONCLUSÕES}

1. No modelo de regressão ajustado para estimar a eficiência de aplicação, as variáveis independentes: velocidade do vento, umidade relativa e temperatura do ar influenciam significativamente na estimativa da variável dependente, com destaque para a velocidade do vento, isoladamente, em interação dupla e tríplice.

2. O modelo estatístico pode ser usado para estimativa de eficiência de aplicação no equipamento testado, dentro das amplitudes observadas nas variáveis climáticas.

\section{LITERATURA CITADA}

Bernardo, S.; Soares, A. A.; Mantovani, E. C. Manual de irrigação. 8.ed. Viçosa: UFV, 2008. 625p.

Heermann, D. F.; Hein, P. R. Performance characteristics of selfpropelled center-pivot sprinkler irrigation system. Transactions of the ASAE, v.27, p.11-14, 1968.

Heinemann, A. B.; Frizzone, J. A.; Pinto, J. M.; Feitosa Filho, J. C. Influencia da altura do emissor na uniformidade de distribuição da água de um sistema tipo pivô central. Pesquisa Agropecuária Brasileira, v.9, p.1487-1491, 1998.

Keller, J.; Bliesner, R. D. Sprinkler and trickle irrigation. New York: Van Nostrand Reinhold. 1990. 280p.

King, B. A.; Wall, R. W.; Karsky, T. F. Center-pivot irrigation system for independent site-specific management of water and chemical application. Applied Engineering in Agriculture, v.25, n.2, p.187-198, 2009.

Lima, S. C. R. V.; Frizzone, J. A.; Costa, R. N. T.; Souza, F.; Pereira, A. S.; Machado, C. C.; Valnir Júnior, M. Curvas de desempenho de válvulas reguladoras de pressão novas e com diferentes tempos de utilização. Revista Brasileira de Engenharia Agrícola e Ambiental, v.7, n.2, p.201-209, 2003.

Neter, J.; Wasserman, W. Applied linear statistical models. Homewood: Richard D. Irwin, 1974. 842p.

Oliveira, A. S. de; Pereira C. A. F.; Paz, V. P. S.; Santos, C. M. Avaliação do desempenho de sistemas pivô central na região oeste da Bahia. Irriga, v.9, n.2, p.126-135, 2004.

Olson, B. L. S.; Rogers, D. H. Comparing drag hoses verses sprinklers on corn irrigated by a center pivot. Applied Engineering in Agriculture, v.24, n.1, p.41-45, 2008.

Peters, R. T.; Evett, S. R. Automation of a center pivot using the temperature-time-threshold method of irrigation scheduling. Journal of Irrigation and Drainage Engineering, v.134. n.3, p.286-291, 2008.

Pinto, J. M.; Silva, C. L.; Oliveira, C. A. S. Influência de variáveis climáticas e hidráulicas no desempenho da irrigação de um pivô central no oeste baiano. Engenharia Agrícola, v.26, n.1, p.76-85, 2006.

Zocoler, J. L.; Cesar, V. E. L.; Vanzela, S. L. Efeito da posição relativa da linha lateral de um equipamento de irrigação do tipo pivô central na uniformidade de distribuição de água e eficiência de irrigação. Engenharia na Agricultura, v.12, n.4, p.290-297, 2004. 